\title{
Nutritional aspects of endurance exercise in humans
}

\author{
BY R. J. MAUGHAN \\ University Medical School, Foresterhill, Aberdeen AB9 2ZD
}

\begin{abstract}
A sedentary life is associated with an increased incidence of a number of disease states, including cardiovascular disease and obesity, and concern is often expressed about the trend towards a decline in the level of physical activity undertaken by the general population. For a significant part of the population, however, daily life still involves a substantial amount of exercise; this is especially true for those living in non-industrialized countries. In other regions, the decrease in the need for hard physical labour on an occupational basis has resulted in a sedentary lifestyle for most of the population, but a need for regular exercise appears to persist in some individuals. Although they have been spared the need to work in order to obtain food, they choose to substitute exercise on a recreational basis. Increased attention is now being paid to the nutritional implications of exercise, and especially of participation in recreational sporting activities which involve prolonged strenuous exercise.

Any physical activity will increase energy expenditure and, therefore, will affect energy balance, although the role of exercise in weight control is still widely debated. Exercise also has some specific effects on the requirements for individual nutrients, but again the nutritional implications of exercise participation are often misunderstood and misrepresented.
\end{abstract}

\section{EXERCISE AND ENERGY BALANCE}

Body weight normally remains remarkably constant throughout adult life, indicating that energy intake is closely matched to expenditure, although there is often a trend towards an increased body mass and body fat content with increasing age. It is not clear, however, that overweight and obesity are associated with an abnormally high food intake or with a low level of physical activity, at least in the early stages of weight gain (Stock \& Rothwell, 1982). Physical activity is generally restricted in established obesity (Durnin, 1984), but this is balanced to some degree by the increased energy cost of weight-bearing exercise (Blair \& Buskirk, 1987). Although elite athletes in training for endurance events, such as marathon runners, are invariably lean, it is not clear whether more moderate levels of exercise play an important role in the regulation of energy balance. For many recreational exercisers the motivation to participate is a belief that exercise will help to reduce body fat content, or at least to limit the increase that would otherwise occur.

There are several possible effects of exercise on energy balance. A negative energy balance may be favoured by the increased energy expenditure involved in the exercise itself, but there is evidence that metabolic rate may remain elevated for some time after the exercise ceases, and this will increase the energy cost associated with a bout of exercise. The thermogenic effect of food ingested during the post-exercise period may be potentiated, and this also will have a negative effect on overall energy balance. Exercise may also affect appetite and, hence, energy intake, and it is possible that hard exercise 
may reduce the amount of activity which the individual undertakes during the remainder of the day.

The energy cost of exercise is often dismissed as having a negligible effect on overall energy balance. For an activity such as walking or running the energy cost is independent of speed, but is determined by the distance covered and body weight, and amounts to about $4 \mathrm{~kJ} / \mathrm{kg}$ per $\mathrm{km}$. It is often recommended that 20-30 min of moderate intensity exercise three times weekly is sufficient exercise to confer some protection against cardiovascular disease: if this exercise is in the form of jogging, the energy expenditure will be about $4 \mathrm{MJ}$ (about $1000 \mathrm{kcal}$ ) per week for the average $70 \mathrm{~kg}$ individual. The energy cost of running a marathon is equivalent only to about $12 \mathrm{MJ}$. However, even a small daily contribution from exercise to total daily energy expenditure will have a cumulative effect on a long-term basis (Harger et al. 1974). For obese individuals, whose exercise capacity is low, the role of physical activity in raising energy expenditure is necessarily limited, but this effect is offset to some degree by the increased energy cost of weight-bearing activity.

The metabolic rate falls rapidly when exercise stops, but remains above the resting level for some time. Depending on the magnitude and duration of the excess postexercise $\mathrm{O}_{2}$ consumption (Gaesser \& Brooks, 1984), it may or may not have a significant effect on the total energy cost of exercise. Some investigators have found a sustained increase in $\mathrm{O}_{2}$ consumption after exercise, but this has generally been seen only where the intensity of the effort was high and the duration prolonged (for a review of these studies, see Bahr, 1992). Although this may have an effect on the athlete engaged in hard training, it appears that this effect is unlikely to be significant for the recreational exerciser. There is also some doubt about the relevance of the observations that exercise may potentiate the thermogenic effect of food consumed in the post-exercise period (Editorial, 1988).

The effects of exercise on appetite and energy intake are also unclear. A period of activity may result in a stimulation of the appetite, leading to an increase in the energy intake; the magnitude of the increased intake may exceed the total energy expenditure of the activity itself (Wilmore, 1983). There are, however, reports that exercise may lead to a suppression of appetite (Reger et al. 1984), and a modest training programme involving energy expenditure of $800 \mathrm{~kJ}$ three times weekly has been reported to have no effect on energy intake (Dickson-Parnell \& Zeichner, 1985).

In a recent study (Maughan et al. 1989) of runners and sedentary individuals who were in steady-state with respect to physical activity levels and body weight, a significant $(P<0.01)$ relationship between energy intake and training load (expressed as miles per week run in training) was observed (Fig. 1): there was also a significant $(P<0 \cdot 001)$ inverse relationship between the training load and body fat content (Fig. 2). If body weight and performance levels are to be maintained, the high rate of energy expenditure of athletes in training must be matched by a high energy intake. Available information for most athletes suggests that they are in energy balance within the limits of the techniques used for measuring intake and expenditure. This is to be expected as a chronic deficit in energy intake would lead to a progressive loss of body mass. However, findings for women engaged in sports where a low body weight, and especially a low body fat content, are important, including events such as gymnastics, distance running and ballet, consistently show a lower than expected energy intake. There is no obvious physiological explanation for this finding other than methodological errors in the 


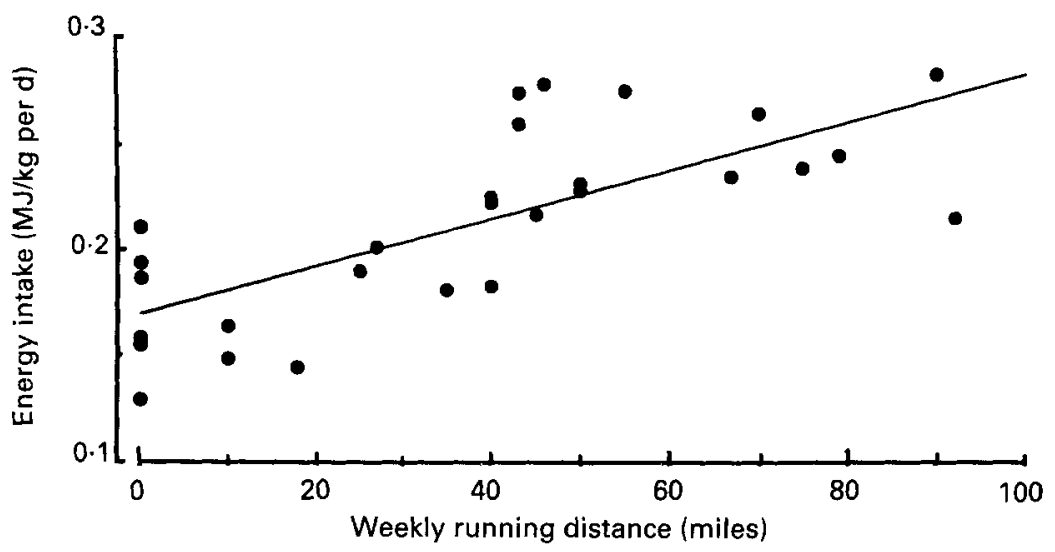

Fig. 1. A significant relationship existed between energy intake and training load (expressed as miles per week run in training) in runners and sedentary individuals who were in steady-state with respect to physical activity levels and body weight: $r 0.52, P<0 \cdot 01$.

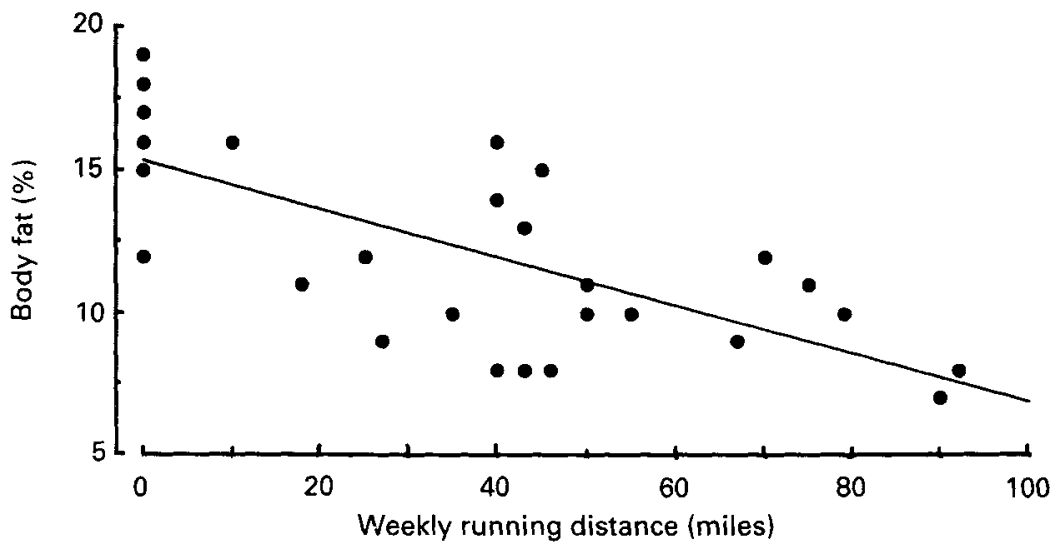

Fig. 2. There was a significant inverse relationship between the training load (expressed as miles per week run in training) and body fat content in runners and sedentary individuals who were in steady-state with respect to physical activity levels and body weight: $r-0.68, P<0 \cdot 001$.

calculation of energy intake and expenditure, but it seems odd that these should apply specifically to this group of athletes. Many of these women do, however, have a very low body fat content; a body fat content of less than $10 \%$ is not uncommon in female long-distance runners. Secondary amenorrhoea, possibly related more to the training regimen than to the low body fat content, is common in these women, but is usually reversed when training stops.

Extreme endurance activities which involve very high levels of energy expenditure on a daily basis are now rarely encountered in occupational tasks. Dill (1936) reported that the average daily metabolic rate of lumberjacks was about four times the basal metabolic rate, and similar values have been reported elsewhere, suggesting that this may be close 
Table 1. Estimated daily energy balance in an elite endurance athlete who ran a total distance of $960 \mathrm{~km}$ in a period of $5 \mathrm{~d} 5 \mathrm{~h} 7 \mathrm{~min}$ (From Rontoyannis et al. 1989)

\begin{tabular}{ccccc}
\hline \hline Day & $\begin{array}{c}\text { Distance } \\
(\mathrm{km})\end{array}$ & $\begin{array}{c}\text { Energy output } \\
(\mathrm{MJ})\end{array}$ & $\begin{array}{c}\text { Energy intake } \\
(\mathrm{MJ})\end{array}$ & $\begin{array}{c}\text { Energy balance } \\
(\mathrm{MJ})\end{array}$ \\
\hline 1 & 270 & $64 \cdot 0$ & $57 \cdot 4$ & $-6 \cdot 6$ \\
2 & 193 & $44 \cdot 8$ & $35 \cdot 8$ & $-9 \cdot 0$ \\
3 & 152 & $37 \cdot 2$ & $52 \cdot 9$ & $15 \cdot 7$ \\
4 & 165 & $40 \cdot 8$ & $32 \cdot 5$ & $-8 \cdot 3$ \\
5 & 135 & $32 \cdot 2$ & $52 \cdot 1$ & $19 \cdot 9$ \\
6 & 45 & $10 \cdot 6$ & $2 \cdot 3$ & -8.3 \\
\hline
\end{tabular}

to the upper limit of physical exercise that can be sustained on a long-term basis. In the short term, sporting activities can involve much higher rates of energy output; the world record for distance run in $24 \mathrm{~h}$ is $286 \mathrm{~km}$, which requires an energy expenditure of about $80 \mathrm{MJ}(20000 \mathrm{kcal})$. Such an effort, however, results in considerable depletion of the body's energy reserves, and must be followed by a period of recovery.

Very high levels of daily energy expenditure are more often a feature of training than of competition, but there are some competitive events which require high levels of activity to be sustained for many consecutive days. One of the most obvious examples is the multi-stage cycle tour, of which the most famous is the Tour de France. Measurements on some of the competitors have shown that they manage to maintain body weight in spite of a mean daily energy expenditure of $32 \mathrm{MJ}(8000 \mathrm{kcal})$ sustained over a 3-week period (Westerterp \& Saris, 1991). They suggested that those cyclists who were unable to meet the daily energy requirement were unable to complete the race. In multi-day running events it appears that intake and expenditure may be less well balanced, and there is a tendency in these races for performances to deteriorate over time (Table 1).

\section{EFFECTS OF ENDURANCE EXERCISE ON THE REQUIREMENT FOR SPECIFIC NUTRIENTS}

The energy requirements of training and competition are largely met by oxidation of fat and carbohydrate, with only a small contribution from protein. Exercise, whether it is long-distance running, aerobics or weight training, will cause an increased rate of protein oxidation compared with the resting state (Lemon, 1991). Although the contribution of protein oxidation to energy production during the exercise period may decrease to about $5 \%$ of the total energy requirement, compared with about $10-15 \%$ (i.e. the normal amount of protein in the diet) at rest, the absolute rate of protein degradation is increased during exercise. This leads to an increase in the minimum daily protein requirement, and an intake of $1.2-1.7 \mathrm{~g} / \mathrm{kg}$ per $\mathrm{d}$ is recommended for athletes (Lemon, 1991). This is $50-100 \%$ in excess of the current recommended intake for sedentary individuals, but will normally be met if a varied diet adequate to meet the increased energy expenditure is consumed. In spite of this, however, many athletes ingest large quantities of high-protein foods and expensive protein supplements; daily protein intakes of up to $400 \mathrm{~g}$ are not unknown in some sports. Disposal of the excess $\mathrm{N}$ is theoretically a problem if renal function is compromised, but there does not appear to be any evidence that excessive protein intake among athletes is in any way damaging to health. 
The higher the intensity of exercise, the greater the reliance on carbohydrate as a fuel; at an exercise intensity corresponding to about $50 \%$ of an individual's maximum $\mathrm{O}_{2}$ uptake $\left(V_{\mathrm{O}_{2} \text { max }}\right)$, approximately two-thirds of the total energy requirement is met by fat oxidation, with carbohydrate oxidation supplying about one-third. If the exercise intensity is increased to about $75 \%$ of $V_{\mathrm{O}_{2} \max }$, the total energy expenditure is increased, and carbohydrate is now the major fuel. If carbohydrate is not available, or is available in only a limited amount, the intensity of the exercise must be reduced to a level where the energy requirement can be met by fat oxidation.

The primary need for the athlete in training, therefore, is for the carbohydrate intake to be sufficient to enable the training load to be sustained at the high level necessary to produce an adaptive response. During each strenuous training session, substantial depletion of the glycogen stores in the exercising muscles and in the liver takes place. If this carbohydrate reserve is not replenished before the next training session, the intensity of the work must be reduced, leading to corresponding decrements in the training response. Any athlete training hard on a daily basis can readily observe this; if a low-carbohydrate diet, adequate in energy but consisting mostly of fat and protein, is consumed after training, it will be difficult to repeat the same training load on the following day.

Feeding a high-fat, low-carbohydrate diet for prolonged periods has been shown to increase the capacity of muscle to oxidize fat and hence improve endurance capacity in the rat (Miller et al. 1984), but may not be effective in man; similarly short-term fasting increases endurance capacity in the rat (Dohm et al. 1983), but results in a decreased exercise tolerance in man (Maughan \& Gleeson, 1988). It has been shown that a high-carbohydrate diet ( $70 \%$ of energy intake as carbohydrate) enabled runners who were training for $2 \mathrm{~h} / \mathrm{d}$ to maintain muscle glycogen levels, whereas if the carbohydrate content was only $40 \%$, a progressive fall in muscle glycogen content was observed (Costill, 1988). Similar results have recently been reported for cycling and running exercise carried out over a $7 \mathrm{~d}$ period (Sherman et al. 1993). A dietary carbohydrate intake of 500-600 g may be necessary to ensure adequate glycogen resynthesis (Coyle, 1991). When exercise of shorter duration and lower intensity is carried out, the requirement for dietary carbohydrate will, of course, be less. Where the aim of participation in exercise is to reduce body fat mass, a balance between intensity and duration must be achieved: the lower the intensity the greater the proportion of the total energy expenditure that is accounted for by fat oxidation, but the lower the total energy expenditure and, hence, the greater the duration necessary to achieve a given level of energy expenditure.

\section{WATER AND ELECTROLYTE REQUIREMENTS}

The major causes of fatigue during prolonged exercise are depletion of substrate stores, especially muscle glycogen, and problems associated with thermoregulation and fluid balance. Mild dehydration will impair exercise capacity and prevent the athlete from achieving optimum performance. Severe dehydration is potentially fatal; exercise in the dehydrated state leads to a rapid elevation of body temperature and the onset of heat illness. There is consequently a real need to ensure adequate fluid intake before, during and after exercise. At high ambient temperatures the only mechanism by which heat can be lost from the body is evaporation. Evaporation of 1 litre of water from the skin will 
remove $2.4 \mathrm{MJ}(580 \mathrm{kcal})$ of heat from the body. For the $2 \mathrm{~h} 30 \mathrm{~min}$ marathon runner with a body weight of $70 \mathrm{~kg}$ to balance his rate of heat production by evaporative loss alone would require sweat to be evaporated from the skin at a rate of about $1.6 \mathrm{l} / \mathrm{h}$ : allowing for loss of sweat that is not evaporated, this requires a sweating rate of about $21 / \mathrm{h}$. This is possible, but would result in the loss of 5 litres of body water, corresponding to a loss of more than $70 \mathrm{~g} / \mathrm{kg}$ body weight for a $70 \mathrm{~kg}$ runner. Along with water, electrolytes are lost in varying amounts, the major constituents of sweat being those of the extracellular space, i.e. $\mathrm{Na}^{+}$and $\mathrm{Cl}^{-}$. Sweat is invariably hypotonic and water is lost in excess of solute.

The composition of drinks to be taken before, during and after exercise will be influenced by the relative importance of the need to supply fuel and water and to replace electrolyte losses; this in turn depends on the intensity and duration of the exercise task, on the ambient temperature and humidity, and on the physiological and biochemical characteristics of the individual. Electrolyte replacement is not normally a priority, but addition of $\mathrm{Na}$ to glucose-containing drinks will promote absorption of glucose and water in the small intestine: this is crucial when rapid replacement is essential, as is the case during exercise (Maughan, 1991). Electrolyte replacement is also important for volume restoration in the post-exercise period.

\section{EFFECTS OF EXERCISE ON MICRONUTRIENT REQUIREMENTS}

With regular strenuous training there must be an increased total food intake to balance the increased energy expenditure. Provided that a reasonably normal diet is consumed, this will supply more than adequate amounts of protein, minerals, vitamins and other dietary requirements. There is no good evidence at present to suggest that specific supplementation with any of these dietary components is necessary for those who exercise regularly or that it will improve performance in endurance events. A diet which provides sufficient energy to meet the needs of a sedentary individual consuming $4 \mathrm{MJ} / \mathrm{d}$ may fail to provide adequate amounts of some of the micronutrients, but the same selection of foods, eaten in greater quantities, may meet the requirements of an athlete taking 12-15 MJ/d. Because of their busy lifestyle and need for a high energy intake, most athletes obtain a significant part of their total energy intake in the form of snacks and convenience foods; there is, however, no evidence that this pattern of eating is harmful. For the individual who has to fit an exercise programme into a busy day, it is inevitable that changes to eating patterns must be made, but these need not compromise the quality of the diet.

The only exceptions to the generalization about dietary supplements may be Fe and, in the case of very active women, $\mathrm{Ca}$. In spite of the role played by haemoglobin in $\mathrm{O}_{2}$ transport, highly-trained endurance athletes, both men and women, commonly have low circulating haemoglobin levels; this is a dilutional effect rather than a true anaemia, and total erythrocyte mass is normally elevated due to an increased blood volume (Weight et al. 1991). This may be considered to be an adaptation to the trained state, but hard training may result in an increased Fe loss, increasing the dietary $\mathrm{Fe}$ requirement. Exercise tolerance is impaired in the presence of anaemia, but low serum folate and serum ferritin levels are not associated with impaired performance, and correction of these deficiencies does not influence indices of fitness in trained athletes (Newhouse et al. 1989). Because of the Fe loss associated with menstruation, women are generally at more 
risk of Fe deficiency than men, and the increased demand for dietary Fe is a particular concern for women who train on a regular basis.

Moderate exercise has been reported to increase bone mineral density in both men and women (Lane et al. 1986), and this may be a significant benefit of exercise for most recreationally active women. Hard training, however, may reduce circulating oestrogen levels and, hence, accelerate bone loss, and there have been many reports of reduced bone density, and an associated increase in skeletal trauma, in elite female distance runners (Marcus et al. 1985). For these athletes, an adequate dietary Ca intake should be ensured, although Ca supplements themselves will not reverse bone loss while oestrogen levels remain low.

\section{REFERENCES}

Bahr, R. (1992). Excess postexercise oxygen consumption - magnitude, mechanisms and practical implications. Acta Physiologica Scandinavica 144, Suppl. 605, 1-70.

Blair, S. \& Buskirk, E. R. (1987). Habitual daily energy expenditure and physical activity levels of lean and adult-onset and child-onset obese women. American Journal of Clinical Nutrition 24, 1410-1417.

Costill, D. L. (1988). Carbohydrates for exercise: dietary demands for optimal performance. International Journal of Sports Medicine 9, 1-18.

Coyle, E. (1991). Timing and method of increased carbohydrate intake to cope with heavy training, competition and recovery. Journal of Sports Sciences 9, 29-52.

Dickson-Parnell, B. E. \& Zeichner, S. (1985). Effects of a short-term exercise program on caloric consumption. Health Psychology 4, 437-438.

Dill, D. B. (1936). The economy of muscular exercise. Physiological Reviews 14, 263-291.

Dohm, G. L., Tapscott, E. B., Barakat, H. A. \& Kasperek, G. J. (1983). Influence of fasting on glycogen depletion in rats during exercise. Journal of Applied Physiology 55, 830-833.

Durnin, J. V. G. A. (1984). Some problems in assessing the role of physical activity in the maintenance of energy balance. In Current Topics in Nutrition and Disease, pp. 101-113 [E. Pollit and P. Amante, editors]. New York: AR Liss.

Editorial (1988). Exercise and energy balance. Lancet i, 392-394.

Gaesser, G. A. \& Brooks, G. A. (1984). Metabolic bases of excess post-exercise oxygen consumption: a review. Medicine and Science in Sports and Exercise 16, 29-43.

Harger, B. S., Miller, J. B. \& Thomas, J. C. (1974). The caloric cost of running: its impact on weight reduction. Journal of the American Medical Association 228, 482-483.

Lane, N. E., Bloch, D. A., Jones, H. J., Marshall, W. H., Wood, P. D. \& Fries, J. F. (1986). Long-distance running, bone density and osteoarthritis. Journal of the American Medical Association 255, 1147-1151.

Lemon, P. W. R. (1991). Effect of exercise on protein requirements. Journal of Sports Sciences 9, (special issue), $53-70$.

Marcus, R., Cann, C., Madvig, P., Minkoff, J., Goddard, M. \& Bayer, M. (1985). Menstrual function and bone mass in elite women distance runners. Annals of Internal Medicine 102, 158-163.

Maughan, R. J. (1991). Fluid and electrolyte loss and replacement in exercise. Journal of Sports Sciences 9 , (special issue), 117-142.

Maughan, R. J. \& Gleeson, M. (1988). Influence of a $36 \mathrm{~h}$ fast followed by refeeding with glucose, glycerol or placebo on metabolism and performance during prolonged exercise in man. European Journal of Applied Physiology 57, 570-576.

Maughan, R. J., Robertson, J. D. \& Bruce, A. C. (1989). Dietary energy and carbohydrate intakes of runners in relation to training load. Proceedings of the Nutrition Society 48, 170A.

Miller, W. C., Bryce, G. R. \& Conlee, R. K. (1984). Adaptations to a high-fat diet that increase exercise endurance in male rats. Journal of Applied Physiology 56, 78-83.

Newhouse, I. J., Clement, D. B., Taunton, J. E. \& McKenzie, D. C. (1989). The effects of prelatent/latent iron deficiency on physical work capacity. Medicine and Science in Sports and Exercise 21, 263-268.

Reger, W. E., Allison, T. G. \& Kurucz, R. L. (1984). Exercise, postexercise metabolic rate, and appetite. In Sport, Health and Nutrition, pp. 115-124 [F. I. Katch, editor]. Champaign, Ill: Human Kinetics.

Rontoyannis, G. P., Skoulis, T. \& Pavlou, K. N. (1989). Energy balance in ultramarathon running. American Journal of Clinical Nutrition 49, 976-979. 
Sherman, W. M., Doyle, J. A., Lamb, D. R. \& Strauss, R. H. (1993). Dietary carbohydrate, muscle glycogen, and exercise performance during $7 \mathrm{~d}$ of training. American Journal of Clinical Nutrition 57, 27-31.

Stock, M. \& Rothwell, N. (1982). Obesity and Leanness. London: John Libby.

Weight, L. M., Darge, B. L. \& Jacobs, P. (1991). Athletes' pseudoanaemia. European Journal of Applied Physiology 62, 358-362.

Westerterp, K. \& Saris, W. H. M. (1991). Limits of energy turnover in relation to physical performance, achievernent of energy balance on a daily basis. Journal of Sports Sciences 9, (special issue), 1-15.

Wilmore, J. H. (1983). Appetite and body composition consequent to physical activity. Research Quarterly 54, $415-425$. 